\title{
Foreword
}

One of the many factors involved in the emergence of a common European identity is the evolution of a shared historical awareness. Any such awareness exists at present only in a rudimentary or even distorted form. Research into relationships of cause and effect in such limited areas as the history of banks and other commercial organizations can surely play an important part here. The banking sector in particular, by virtue of its central economic role and comparatively homogeneous structure, offers outstanding scope for historical background research whose findings can claim the interest, not only of those within the industry, but also of a wider public. One of the principal aims of the European Association for Banking History, founded in 1990, is to promote dialogue between banks and the public at large. This Handbook has been produced as part of that endeavour. It is intended for all who are interested in the development of the European banking industry and the distinctive and common features of that development in individual European countries.

Work on this project was initiated in the summer of 1991, when letters were sent to some 330 banks in 19 Western European countries requesting brief articles on their history. Each letter was accompanied by two sample articles illustrating the pattern envisaged. Some two-thirds of the banks thus approached responded favourably to our request. Our special thanks are due to them for their willingness to cooperate. The content and arrangement of individual contributions is the exclusive responsibility of the banks concerned. The articles were written by archivists, staff of public relations or economics departments, and research staff.

The Handbook is divided into sections devoted to individual countries, each section being prefaced by a chapter on the general development of banking in the country concerned. These introductory chapters were written by prominent banking and economic historians. The introductory chapter is followed by the contribution from the country's central bank, and this in turn by the articles received from individual banks; these are arranged in alphabetical order of banks' names. Only in two instances has this pattern been varied. The section on Ireland has no chapter on Irish banking history and, in the section on Iceland, the histories of the individual banks have been incorporated in the general history of banking on the island. We would draw particular attention to the addresses following the individual articles. 


\section{xiv Foreword}

These provide the interested reader with the first-ever survey of bank archives throughout Western Europe and their possible use for research.

No doubt the reader will notice the absence of one or another big bank's name. Unfortunately, and despite considerable efforts in several instances, we were not always successful in gaining contributions from banks still not included. Nevertheless, we believe the Handbook does cover a representative selection of important European banks. Size was not the only major criterion governing selection; depth of tradition, which in some cases extends over more than a century, was also an important consideration. Because of the rapid political and economic changes taking place in Eastern Europe at the start of the project, it was not feasible to include banks in that part of the continent. Perhaps it will be possible to extend the range of banks included in a second edition. Banks whose interest is aroused by the present edition can obtain further information from the offices of the EABH.

The Handbook on the History of European Banks is the first major project realized by our recently founded association. My special thanks are due here to Sabine Freitag, who supervised work on the book through all stages of preparation.

Manfred Pohl December 1993 